\title{
GASTRIC MOTOR AND INHIBITOR RESPONSE TO STIMU- LATION OF THE SYMPATHETIC NERVE IN THE DOG
}

\author{
YOSHIKAZU NAKAZATO, KOJI SAITO AND AKIRA OHGA \\ Department of Pharmacology, Faculty of Velerinary Medicine, Hokkaido University, Sapporo
}

Received for publication October 11, 1969

There are numerous reports concerning the effect of sympathetic nerve stimulation on gastric motility. In most of them, both excitatory and inhibitory effects are observed. Authors have emphasized that such reciprocal effects of sympathetic stimulation depended on the tonic condition of the stomach, the change of the gastric circulation, the types of stimulation, the difference of anesthetics and of types of nerve fibres. The most reasonable interpretation seems to be that the motor response to stimulation of the splanchnic or periarterial nerves is cholinergic (1-4) and the inhibitory one is adrenergic in origin $(3,5-7)$. However, since adrenergic motor response has also been reported (8-11), the problem is more complicated. The aim of the present experiment was to accumulate more detailed information on the causes of the contraction and relaxation of the stomach in response to stimulation of the sympathetic nerve. Recently, it has been reported that the gastric relaxation caused by vagal stimulation was non-adrenergic in origin $(6,7,12-14)$. Therefore, in this paper the gastric responses to stimulation of the splanchnic and periarterial nerves and to close arterial injection of noradrenalinc and isoproterenol were analysed comparatively using the autonomic blocking agents, together with the vagal gastric response serving as a control.

\section{METHODS}

Adult dogs, fasted for 24-48 hours, were used for this experiment. Twenty-five animals were anesthetized with ether and twenty-nine with intravenous injection of pentobarbital $30 \mathrm{mg} / \mathrm{kg}$. Under these anesthesia, the trachea and the femoral artery were cannulated. Polyethylene tubing was also inserted into the cephalic vein for systemic administration of the drugs.

In the animal anesthetized with ether, the spinal cord was transected between $\mathrm{C}_{1}$ and $\mathrm{C}_{2}$ levels and immediately artificial ventilation was started. Bilateral or left adrenal glands and the spleen were removed after ligations of all blood vessels at points nearest to each organ. Under artificial ventilation, the left side of the chest was opened by removing the ribs from 7 th to 13 th. The left greater splanchnic nerve was cut at a point nearest to the rostral portion of the diaphragm and its peripheral end was freed from surrounding tissues for preganglionic sympathetic stimulation. In other cascs periarterial nerves sur- 
rounding the coeliac artery were separated from the arterial wall and used for postganglionic sympathetic stimulation. The dorsal vagal trunk which received contributory branches from both vagus nerves was separated from the oesophageal wall. At the join the branch from the left vagus was cut and used for central vagal stimulation. The other branch from the right vagus also was cut for peripheral stimulation. A thin polyethylene tube was inserted into a branch of the splenic artery for retrograde close gastric arterial injection of the drugs. Noradrenaline and isoproterenol, $0.5 \mathrm{ml}$ in volume, were injected through this tubing and flushed with $0.5-1 \mathrm{ml}$ of heparinized saline.

The recording and stimulating techniques were the same as those previously described (14).

Observations were started at least 2 or 3 hours after the surgical procedures. Throughout the experiments the animals were immobilized by repeated doses of gallamine triethiodide (Flaxedil).

Drugs used were dl-noradrenaline hydrochloride (Sankyo), dl-isoproterenol hydrochloride, atropine sulphate (Merck), hexamethonium bromide (Methobromin, Yamanouchi), bretylium tosylate (kindly supplied by Chugai), guanethidine sulphate (kindly supplied by CIBA), phenoxybenzamine hydrochloride (Tokyokasei) and pronethalol hydrochloride (Alderlin, Sumitomo Chemical).

\section{RESULTS}

1. Types of response to stimulation of the peripheral splanchnic or periarterial nerve and to close arterial injection of noradrenaline and isoproterenol

There was no significant difference between the gastric responses obtained in dogs whose spinal cord was transected under ether inhalation and those whose spinal cord was intact which were anesthetized with pentobarbital. In the following descriptions, therefore, both groups were not differentiated.

The shapes of gastric responses to stimulation of the greater splanchnic nerve and to close arterial injection of noradrenaline $(2-10 \mu \mathrm{g})$ were compared in thirty-three dogs. The responses were varied with the difference of stimulus strength and of animals. Furthermore, in the same animal, it changed form one type of response to another
A

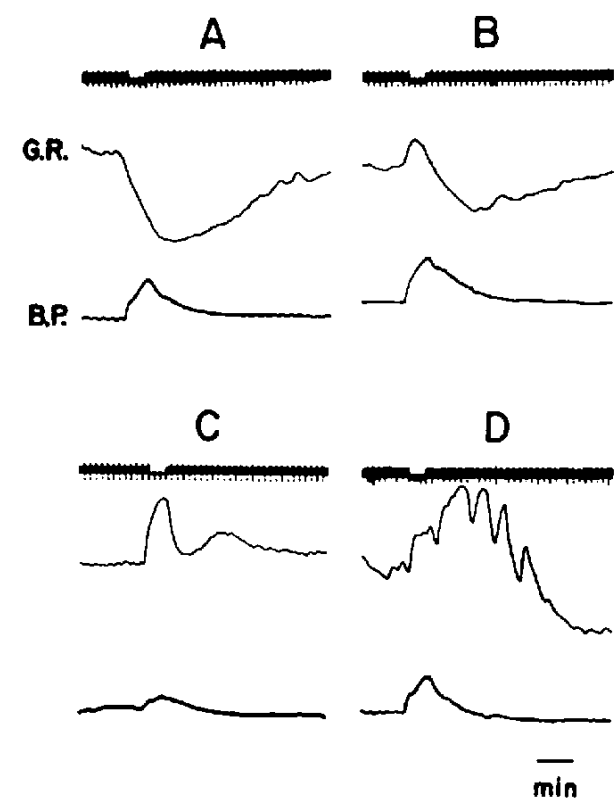

G.R.

Fig. 1. Four main types of gastric response to stimulation of the peripheral splanchnic nerve. In each panel, the upper trace is the time marker, the middle trace the gastric response (G.R.) and the lower trace the systemic blood pressure (B.P.) recorded in the femoral artery. The stimulating period is indicated as a half blank in the time marker. For a detailed explanation of the gastric response, see the text. 
during the course of the observation. Most of them, however, were included in the following four types (Fig. 1). The first type of response (type A) was a relaxation which is common in stimulation of a low strength in the unatropinized animals. The second type (type B) was a biphasic response which consisted of an initial contraction and an after relaxation. The third one (type $\mathrm{C}$ ) was a contraction. The contractions which were seen in the second and third types of response were usually characterized by a single smooth wave. These two types of response were most common in the atropinized animal. In addition to the types of response mentioned above, another one (type $\mathrm{D}$ ) was elicited by stimulation of a high strength only in the unatropinized animal. This type of response was a contraction which was characterized by its peristaltic-like wave and was abolished by atropine. An example of the serial gastrie responses to stimulation of the peripheral

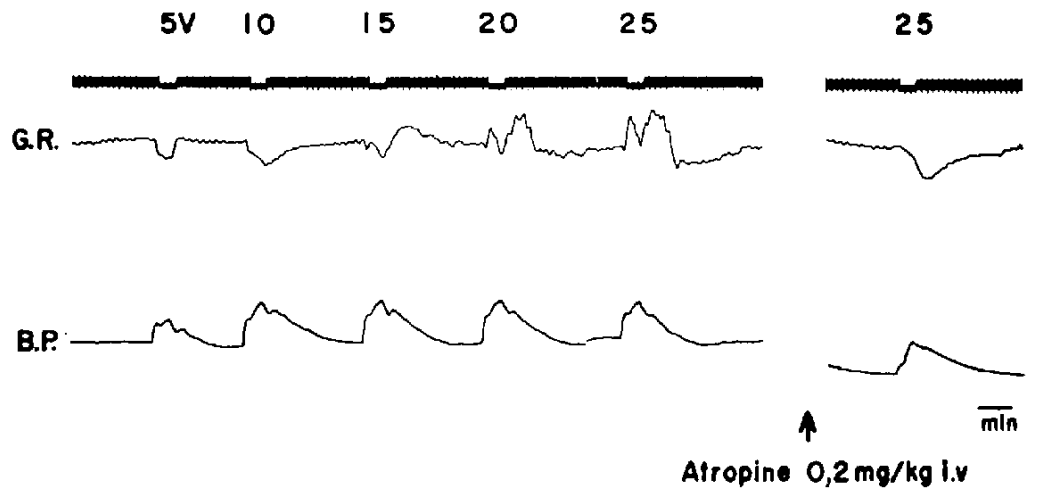

Fig. 2. Gastric responses to stimulation of the peripheral splanchnic nerve at different strengths. Figures above the time marker indicate the strength (voltage) of each stimulation. See the text.

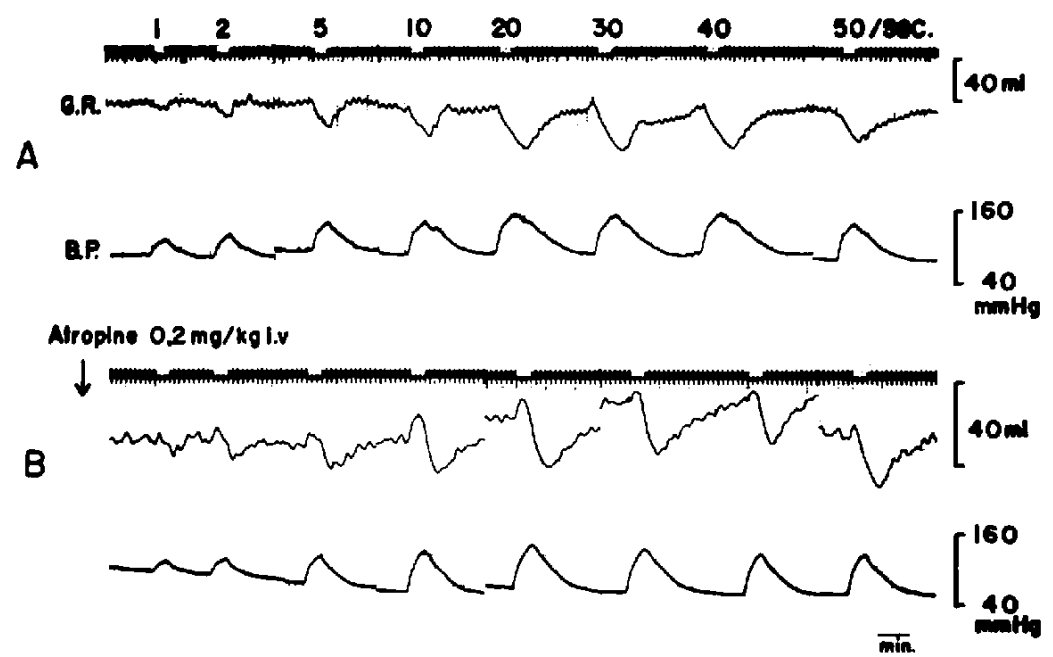

Fig. 3. Gastric responses to stimulation of the peripheral splanchnic nerve at a series of frequencies. A, the responses before atropine, and B, after atropine. Note that the response attained a maximum at a frequency of $20-30$ pulses/sec in both conditions. Figures above the time marker indicate the frequency of each stimulation. 
splanchnic nerve with different strength is shown in Fig. 2. It was noted that the relaxation (type $\mathrm{A}$ ) with stimulation of a low strength was converted into a contraction (type D), when the strength of stimulation was increased. This contraction was abolished by atropine and the relaxation reappeared. Such reversal of the gastric response was never observed after treatment with atropine. The maximum response was obtained when the frequency of stimulation was 20-30 pulses/sec, irrespective of treatment with atropine (Fig. 3). Stimulation of the peripheral splanchnic nerve produced a rise of the systcmic blood pressure at any strength or frequency.

Almost identical responses were caused by stimulation of the periarterial nerve and by close arterial injection of noradrenaline, except atropine-sensitive contraction of type $\mathrm{D}$ was never observed by noradrenaline. On the other hand, close arterial injection of isoproterenol $(2-5 \mu \mathrm{g})$ generally caused a relaxation. From these facts, at least the contraction of type $\mathrm{D}$ may be cholinergic in origin. It was interesting that the rate of the occurrence of the contractions of other types in response to stimulation of the peripheral splanchnic and periarterial nerves
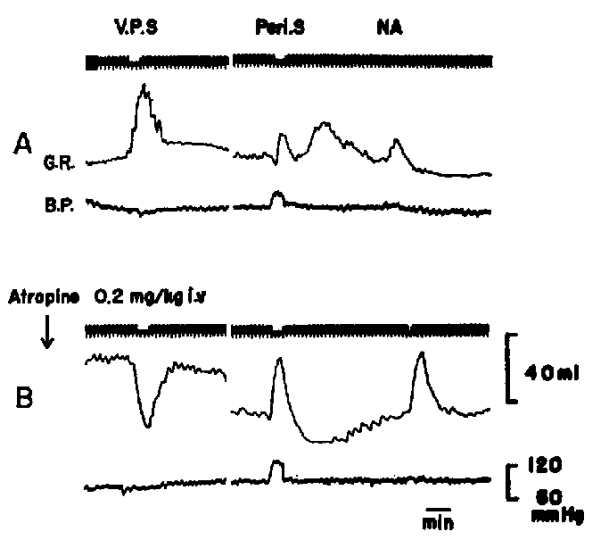

Fig. 4. Effect of atropine on the responses to stimulation of the periarterial nerve and to noradrenaline. A, control responses and $B$, responses after atropine. V.P.S, peripheral vagal stimulation, Peri. S. periarterial nerve stimulation, $\mathrm{NA}$, intra-arterial injection of noradrenaline $5 \mu \mathrm{g}$. Marks of stimulations and close arterial injection of drugs are illustrated above the control responses. The response after blocking agents arc arranged in order of that of the control. Contractions with peristaltic-like waves (type D) caused by periarterial nerve stimulation were converted into a contraction followed by a relaxation (type $B$ ) and that by peripheral vagal stimulation was reversed to a relaxation by treatment with atropine. Note that the initial contraction caused by periarterial nerve stimulation and the contraction of noradrenaline were augmented by atropine.

as well as noradrenaline increased after atropinization. Furthermore, in some instances in which the contraction was already scen before atropine, the amplitude was rather augmented by treatment with atropine (Fig. 4).

2. Effects of drugs on the responses to stimulation of the peripheral splanchnic or periarlerial nerve and to close arterial injection of noradrenaline and isoproterenol

a) Effects of hexamethonium

The effect of hexamethonium on the responses to stimulation of the peripheral splanchnic nerve was somewhat complicated. In most experiments, hexamethonium $(5-20 \mathrm{mg} / \mathrm{kg}$ i.v.) markedly reduced or abolished type A, B and $\mathrm{C}$ responses (Fig. 5 i). While the contraction of type $\mathrm{D}$ was not affected by hexamethonium, but was abolished by atropine as described above. In rare cases, a relatively long-lasting contraction which was insensitive to hexamethonium and atropine was observed. The responses to stimulation of the peri- 
arterial nerve and to noradrenaline and isoproterenol were not affected by hexamethonium whether the animal was treated with atropine or not (Fig. 5 ii).
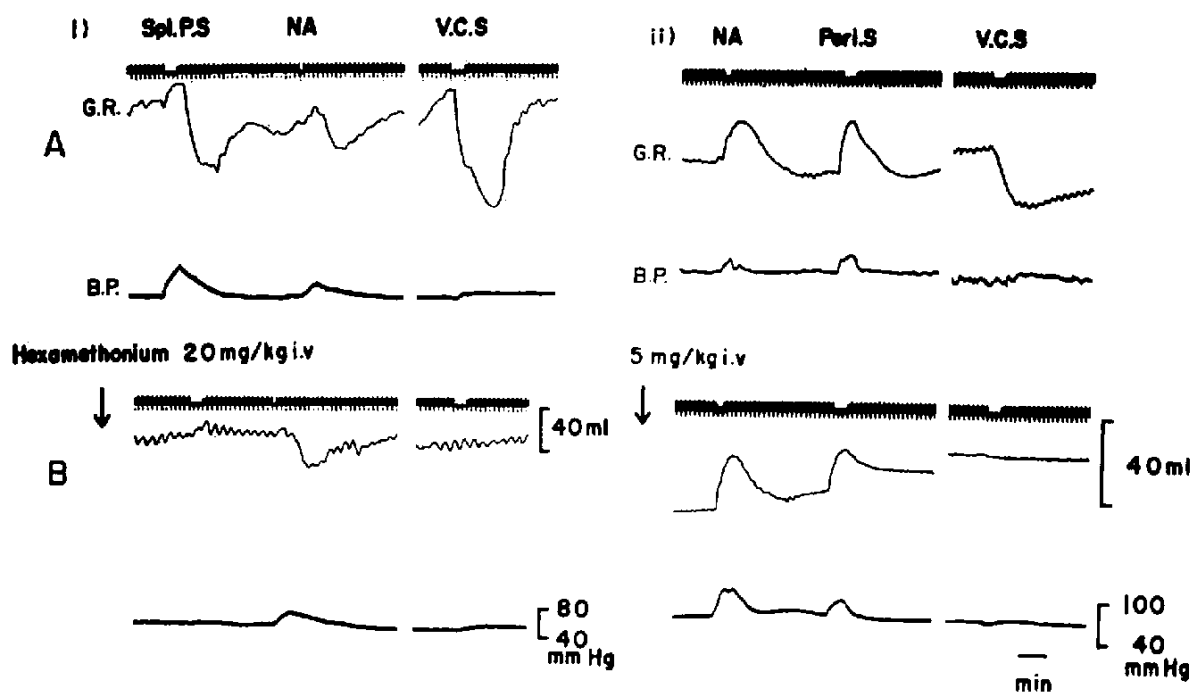

Fic. 5. Effect of hexamethonium on the response to stimulation of the sympathetic nerves and to noradrenaline in atropinized dogs.

i), peripheral splanchnic nerve (preganglionic) stimulation ii), periarterial nerve (postganglionic) stimulation $\mathrm{A}$, control responses and $\mathrm{B}$, responses after hexamethonium. Note that hexamethonium completely abolished the response (type $B$ ) to stimulation of the peripheral splanchnic nerve (Spl.P.S) as well as that to central vagal stimulation (V.C.S) without affecting the contraction (type C) caused by the periarterial nerve stimulation and to noradrenaline. Dose of atropine $0.2 \mathrm{mg} / \mathrm{kg} \mathrm{i.v.}$

A
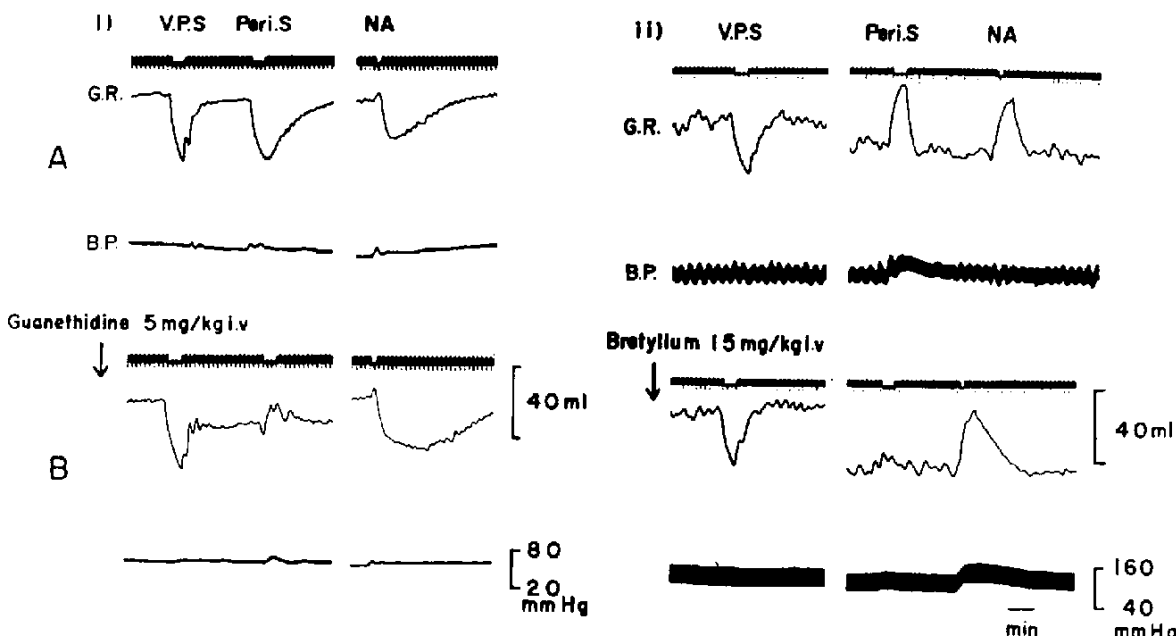

FIG. 6. Effect of the adrenergic neurone blocking agents on the response to stimulation of the periarterial nerve and to noradrenaline in atropinized dogs.

i), effect of guanethidine on the relaxation (type A) ii), effect of bretylium on the contraction (type $\mathrm{G}$ ). A, control responses and $\mathrm{B}$, responses after the adrenergic neurone blocking agents. Note that both blocking agents markedly reduced or abolished only the response to the sympathetic nerve stimulation irrespective of their direction. 
The rise of the blood pressure caused by the peripheral splanchnic nerve stimulation was reduced or abolished by hexamethonium, while the responses caused by the periarterial nerve stimulation and by the drugs were little affected.

b) Effects of brelylium and guanethidine

In thirteen of fifteen atropinized dogs, the gastric responses to stimulation of the peripheral splanchnic or periarterial nerve were markedly reduced or abolished by bretylium (7-15 mg/kg i.v.) or guanethidine $(2.5-15 \mathrm{mg} / \mathrm{kg} \mathrm{i.v.)}$, irrespective of the type of response. In two of them, however, these stimulations produced relatively long-lasting contractions which were not reduced by the blocking agents. On the other hand, the responses caused by the central and peripheral vagal stimulations were little affected by bretylium and guanethidine. The responses to noradrenaline and isoproterenol were also not reduced but rather occasionally augmented. An example is shown in Fig. 6. When these blocking agents were injected before atropine, frequently atropine-sensitive contraction was unmasked. From these data, it was evident that both contraction and relaxation of the stomach caused by stimulation of the peripheral splanchnic or periarterial nerve in the atropinized animal were mainly sympathetic in origin.

The rise of the systemic blood pressure caused by sympathetic stimulation was also decreased or abolished after treatment with bretylium and guanethidine.

c) Effects of phenoxybenzamine and pronethalol

Observations of this series were carried out in seven atropinized dogs. Before treatment with $\alpha$ - and $\beta$-receptor blocking agents, in six of them the responses of type $B$ and $\mathrm{C}$ and only in one of them the response of type $\mathrm{A}$ were caused by stimulation of the periarterial nerve and by noradrenaline. The initial contraction of type $\mathrm{B}$ and the contraction of type $\mathrm{C}$ were reversed to relaxations by treatment with $\alpha$-blocking agent, phenoxybenzamine (15-20 mg/kg i.v.). While the relaxations of type A caused by either nerve stimulation or by noradrenaline and isoproterenol were not affected, but rather augmented. After phenoxybenzamine, therefore, the relaxation was the only type of response to sympathetic stimulation and to noradrenaline and isoproterenol. In three animals which survived after subsequent treatment with $\beta$-blocking agent, pronethalol $(10 \mathrm{mg} / \mathrm{kg}$ i.v.), relaxations which were unmasked or augmented after phenoxybenzamine were reduced or abolished. On the other hand, relaxations caused by central and peripheral vagal stimulations were not reduced by these $\alpha$ - and $\beta$-blocking agents. In a few cases, the vagal relaxations tended to increase more in amplitude after phenoxybenzamine than before.

The behavior of the systemic blood pressure was not always parallel to the gastric response. The rise of the blood pressure by sympathetic stimulation and noradrenaline was reduced, but never caused to fall by phenoxybenzamine (Fig. 7).

These results strongly suggest that in atropinized dogs the contraction of the fundus and body of the stomach caused by sympathetic stimulation and intra-arterial injection of noradrenaline may be mediated by $\alpha$-receptor, while the relaxation may be mediated by $\beta$-receptor. 

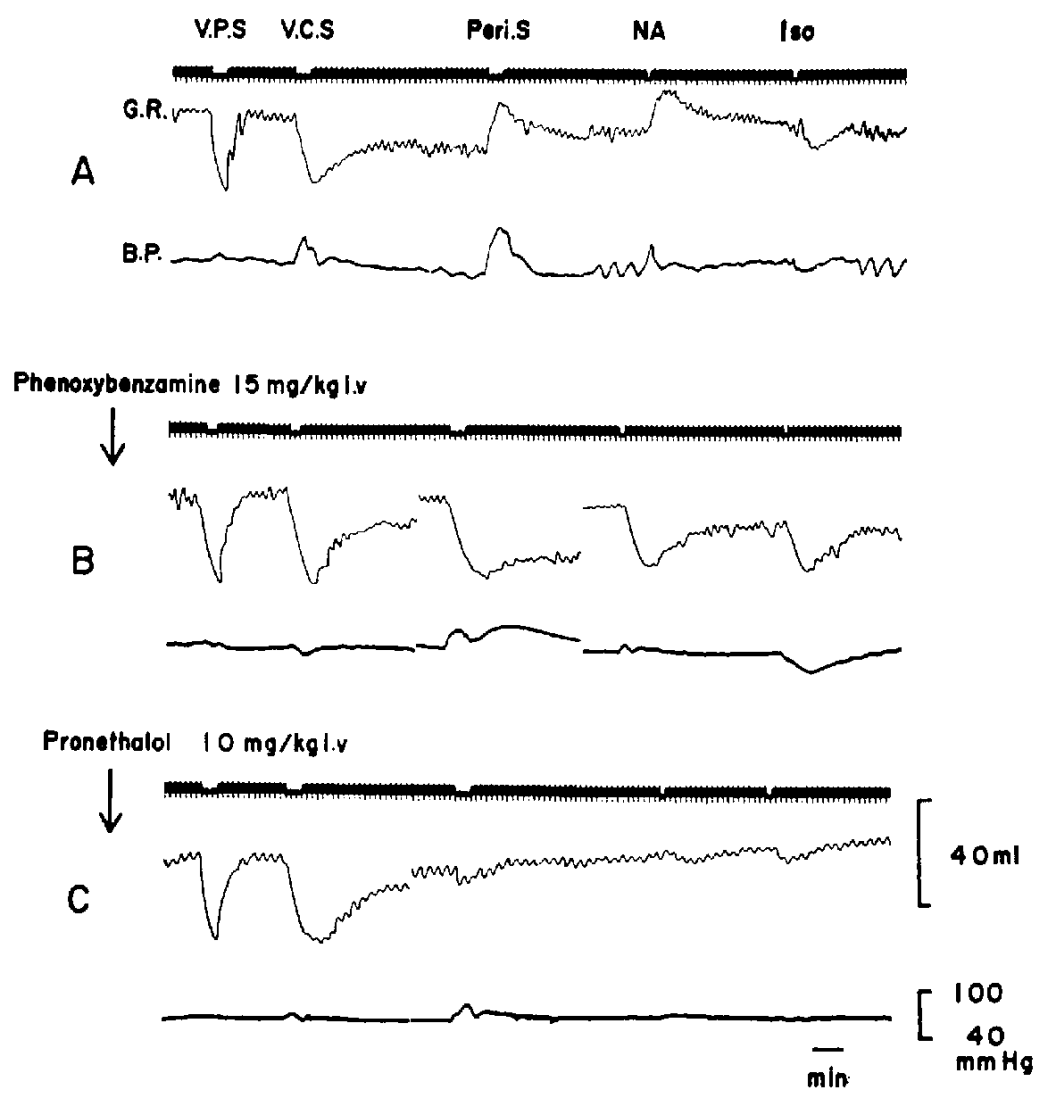

Fig. 7. Effect of adrenergic $\alpha$ - and $\beta$-blocking agents on the response to stimulation of the vagus, periarterial nerve and to noradrenaline and isoproterenol in atropinized dogs. $A$, control responses, $B$, responses after phenoxybenzamine, $C$, responses after phenoxybenzamine plus pronethalol. Note that phenoxybenzamine converted the contraction (type C) caused by stimulation of the periarterial nerve and noradrenaline into a relaxation (type A). These relaxations and that caused by isoproterenol are almost abolished by pronethalol. Vagal relaxations are not reduced by these blocking agents.

\section{DISCUSSION}

The present experiment indicated that the contractions of the stomach produced by stimulation of the greater splanchnic or periarterial nerve were elicited by both cholinergic and adrenergic mechanisms, while the relaxations were mainly adrenergic in origin. Brown, McSwiney and Wadge (1) in in vivo experiment and McSwiney and Robson (2) in in vitro experiment reported that there were both gastric motor and inhibitor fibres in the sympathetic nerve to the stomach of cats and dogs. Using eserine and atropine, Harrison and McSwiney (15) showed that the motor fibres were cholinergic and the inhibitory fibres were adrenergic in cats. This view was supported by Semba and Hiraoka (4) in dogs. On the other hand, some workers have reported that the motor response of the stomach muscle in vivo and in vitro is due to adrenaline and noradrenaline. Most of them attributed the action of adrenaline and noradrenaline to the indirect effect. That is, the direction of the gastric responses to catecholamine was dependent on the tonic con- 
dition of the stomach (10), the change of the blood stream due to vaso-constriction (9) or the presence or absence of vagal tonic supply to the stomach muscle (11). However, there were also the reports which suggested the direct action of catecholamine. According to Smith (8), the sympathetic innervation of the rabbit's and dog's stomach is excitatory in the main. The evidence was that adrenaline usually caused a contraction of the isolated preparation from the body of the dog's stomach and this contraction reversed to the relaxation after treatment with ergotoxine. Brown and McSwiney (16) presumed that the direction of the response to sympathetic stimulation was determined by the rate of the liberation of a specific substance in a cat's stomach. From these reports, it is possible to assume that all of the contractions of the stomach muscle upon stimulation of the sympathetic nerve may not be entirely cholinergic in origin.

In the present experiment, the gastric responses to stimulation of the sympathetic nerve and to close arterial injection of noradrenaline and isoproterenol were observed comparatively. There was no significant difference between those gastric responses obtained in the dogs whose spinal cord was transected under ether inhalation and those which were anesthetized with pentobarbital. Peripheral splanchnic or periarterial nerve stimulation and noradrenaline caused various types (type A, B, C and D) of gastric response, that is relaxation, contraction and contraction followed by relaxation. In addition to these responses, in only a few cases, a long-lasting contraction which was insensitive to the present autonomic blocking agents was produced by stimulation of the sympathetic nerve. Further study of this contraction is required.

Most of the responses to peripheral splanchnic stimulation were abolished by hexamethonium except the atropine-sensitive contraction with a peristaltic-like wave (type D). On the other hand, none of the responses to periarterial nerve stimulation and to the drugs were affected by hexamethonium. This agrees with the findings of Semba and Hiraoka (4), that the atropine sensitive motor response of the stomach to stimulation of the greater splanchnic nerve was not affected by ganglion blocking agents. On the contrary, the adrenergic fibres in this nerve may be preganglionic fibres and their ganglion cells probably located in the cocliac ganglion.

The confusion in earlier research probably results from the view that the contraction caused by sympathetic nerve stimulation was attributed only to unitary mechanism, which is either cholinergic or adrenergic in origin. From the present data, both cholinergic and adrenergic mechanisms must be presumed to be the causes of the contractile response to sympathetic nerve stimulation. Before atropine, the strength of stimulation seemed to be an important factor in determining the direction of the response as suggested by Brown, McSwiney and Wadge (1) and McSwiney and Robson (2). In most cases, when stimulation of a low strength was delivered, a rclaxation (type A) was obtained. With an increase in the strength, this relaxation decreased and finally reversed to a contraction with peristaltic-like waves (type D). This contraction was also observed after bretylium and guanethidine, but abolished by atropine. In the atropinized animals, however, in addition to type $A$, another type of response, contraction (type $G$ ) or contraction followed 
by relaxation (type B) was observed. Most, but not all, of the contraction after atropine was a single smooth one and there was no response like type $\mathrm{D}$ which was observed before atropine. As described above, atropine-sensitive contraction may be cholinergic in origin as shown by Harrison and McSwiney (15) and Semba and Hiraoka (4). Noradrenaline also caused the responses of type $A, B$ and $C$. The shapes of these responses were very similar to those produced by sympathetic stimulation in atropinized animals. Most of the atropine-resistant responses to stimulation of the sympathetic nerve were selectively abolished or reduced by bretylium and guanethidine regardless of the type of the response. This may indicate that these responses are adrenergic in origin. The threshold of the cholinergic fibres which was presumed to be included in the greater splanchnic and periarterial nerves was higher than that of the adrenergic fibres responsible for gastric motility.

According to Ahlquist and Levy (17), both $\alpha$-and $\beta$-adrenergic receptors in the canine ileum subserve relaxation or inhibition. Recently, several authors have described that an excitatory and inhibitory $\alpha$-receptor may be localized in the cholinergic nerve and an inhibitory $\beta$-receptor in the smooth muscle of the cat's oesophagus and the guinea-pig ileum (18-20). Their evidence was that the excitatory effect of $\alpha$-stimulants was inhibited by atropine and augmented by eserine. There are no detailed studies on the role and the localization of the adrenergic receptors in the fundus and the body of the dog's stomach. In the present experiment, the atropine-resistant contractions caused by sympathetic stimulation and noradrenaline were reversed to a relaxation by phenoxybenzamine. This result agreed with the finding of Smith (8) that ergotoxine abolished the contractions and unmasked the relaxation in response to adrenaline of the isolated strips from the dog's stomach. After phenoxybenzamine, therefore, only the relaxation was caused by sympathetic stimulation and noradrenaline. These relaxations and that caused by isoproterenol were reduced or abolished by subsequent administration of pronethalol. From these facts, it secms most likely that atropine-resistant contractions caused by sympathetic stimulation and noradrenaline are mediated by $\alpha$-receptor, while relaxation by $\beta$-receptor. There was no sign of relaxation which was inhibited by phenoxybenzamine. This might evidence that $\alpha$-receptor of these portions of the dog's stomach mainly mediates the excitation. Furthermore, the adrenergic contraction was never reduced but rather augmented by atropine even at the same tonic level, although the mechanism was still unknown. This might indicate that in the fundus and the body of the dog's stomach $\alpha$-and $\beta$-receptor are located in the smooth muscle.

At one time, the change of the gastric blood stream and the tonic condition of the stomach muscle have been suggested as the essential factors in determining the direction of the gastric response to sympathetic stimulation or catecholamine (21). In this experiment, the behavior of the gastric response after treatment with adrenergic neurone and receptor blocking agents was not always parallel to that of the blood pressure. That is, the gastric response was reversed by $\alpha$-blocker, the pressor response of the systemic blood pressure only reduced. Jansson and Martinson (22) described that, when the stimuli employed to the vagus are intense enough to activate both the excitatory and inhibitory 
fibres, the direction of the gastric response depends on the tonus of the stomach. When, however, only excitatory fibres are stimulated, the response will be only excitatory irrespective of the tonic level. Also in the present experiment, the tonicity of the stomach might contribute to the direction of the gastric response to sympathetic stimulation by determining the volume of the intragastric cavity left for contraction or relaxation as suggested by Martinson and Muren (23). If this is true, it is not suprising that at a high tonic level, the relaxation due to the activation of $\beta$-receptor and at a low level, the contraction by activation of $\alpha$-receptor may be more prominent, respectively. Therefore, we cannot presume that the direction of the gastric response to sympathetic stimulation and catecholamine are primarliy dependent on the change of the blood stream or the tonicity of the stomach.

\section{SUMMARY}

1. The responses of the fundus and the body of the dog's stomach to stimulations of the peripheral splanchnic, periarterial nerves and to gastric arterial injection of noradrenaline and isoproterenol were analysed comparatively using atropine, hexamethonium, bretylium, guanethidine, phenoxybenzamine and pronethalol.

2. Before treatment with atropine, the type of response to stimulation of the peripheral splanchnic or periarterial nerve depended mainly on the strength of the stimulation. With stimulation at a low strength a relaxation was produced and at a high strength a contraction, which was superimposed by peristaltic-like waves. The main part of this contraction was abolished by atropine.

3. After atropine, the responses were a relaxation, a contraction or a contraction followed by a relaxation. This atropine-resistant contraction was characterized by a single smooth wave.

4. The response to noradrenaline was identical with that caused by sympathetic nerve stimulation in the atropinized animal. In the same animal, the type of response to stimulation of the sympathetic nerves and to noradrenaline was usually the same.

5. In the atropinized animal, hexamethonium abolished most of the responses to stimulation of the peripheral splanchnic nerve without affecting the responses to periarterial nerve stimulation and to noradrenaline and isoproterenol.

6. In the atropinized animal, bretylium and guanethidine effectively reduced or abolished the responses to stimulation of the sympathetic nerves without affecting the responses to noradrenaline and isoproterenol.

7. The atropine-resistant contraction caused by stimulation of the sympathetic nerve and by noradrenaline was reversed to a relaxation by phenoxybenzamine. These relaxations and that caused by isoproterenol were markedly reduced or abolished by subsequent doses of pronethalol. On the contrary, the responses to vagal stimulations were not affected by either receptor blocking agent.

8. It is concluded that the contraction of the fundus and the body of the dog's stomach caused by stimulation of the peripheral splanchnic or periarterial nerve may be mediated 
by both the cholinergic mechanism and the adrenergic $\alpha$-receptor, while the relaxation may be mainly mediated by $\beta$-receptor.

Acknowledgment: We thank Mr. T. Kitamura for his technical assistance.

\section{REFERENCES}

1) Brown, G.L., MaSwiney, B.A. and Wadge, W.J.: J. Physiol. 70, 253 (1930)

2) McSwiney, B.A. And Robson, J.M.: J. Physial. 71, 194 (1931)

3) Eliasson, S.: Acta physiol. scand. 26, Suppl. 95 (1952)

4) Semba, T. and Hiraoka, T.: Jap. J. Physiol. 7, 64 (1957)

5) Paton, W.D.M. and Vane, J.R.: J. Physiol. 165, 10 (1963)

6) Martinson, J.: Acta physiol. scand. 64, 453 (1965)

7) Campelel, G.: J. Physiol. 185, 600 (1966)

8) Sмith, M.I.: Am. J. Physiol. 46, 232 (1918)

9) Veach, H.O.: J. Physiol. 60, 457 (1925)

10) McSwiney, B.A. And Brown, G.L.: J. Physiol. 62, 52 (1926)

11) Muren, A.: Acta physiol. scand. 39, 195 (1957)

12) Bülbring, E. and Gershon, M.D.: J. Physiol. 192, 823 (1967)

13) Ohga, A., Nakazato, Y. and Saito, K.: J. Physiol. Soc. Japan. 30, 92 (1969)

14) Ohga, A., Nakazato, Y. and Satto, K.: Jap.J. Pharmac. 20, 116 (1970)

15) Harrison, J.S. And McSwiney, B.A.: J. Physiol. 87, 79 (1936)

16) Brown, G.L. And McSwiney, B.A.: J. Physiol. 74, 179 (1932)

17) Ahlquist, R.P. And Levy, B.: J. Pharmac. exp. Ther. 127, 146 (1959)

18) Christensen, J. and Daniel, E.E.: Am. J. Physial. 221, 387 (1966)

19) Christensen, J.: Handbook of Physiology, Section 6: Alimentary Canal, Vol. IV, Edited by Code, C.F., p. 2325, American Physiological Society, Washington, D.C. (1968)

20) Kosterlitz, H.W. and Watt, A.J.: J. Physiol. 177, 11 P (1965)

21) McSwiney, B.A.: Physiol. Rev. 11, 478 (1931)

22) Jansson, G. and Martinson, J.: Acta physiol. scand. 63, 351 (1965)

23) Martinson, J. and Muren, A.: Acto physiol. scand. 57, 309 (1963) 